\title{
A Model for a Novel Communication Training Program Focused on Accent Modification for International Medical Professionals
}

\author{
Poonam Khurana, MD, FAAP (Corresponding author) \\ Assistant Professor of Clinical Pediatrics \\ Director, American English for Internationals Program \\ Indiana University School of Medicine, Indianapolis, Indiana, USA \\ Tel: 1-317-962-2275 E-mail: pkhurana@iu.edu \\ Edgar Huang, PhD, MFA \\ Associate Professor, School of Informatics and Computing \\ Indiana University, Indianapolis, Indiana, USA \\ Tel: 1-317-278-4108 E-mail: ehuang@iupui.edu
}

Received: July 14, 2014 Accepted: August 22, $2014 \quad$ Published: August xx, 2014

doi:10.5296/jet.v2i1.6261 URL: http://dx.doi.org/10.5296/jet.v2i1.6261

\begin{abstract}
Effective communication is a core component of quality healthcare. It is a major determinant of patient satisfaction as well as career advancement for physicians and researchers. The demographics of the healthcare scenario in the United States have changed in the last decade. There is a dramatic increase in the number of International medical graduates (IMGs). While IMGs bring with them all their knowledge and expertise, their pronunciation and intonation patterns often create a barrier to their communication. Paradoxically, very few programs exist in the U.S. to provide communication skills training geared to the IMGs' needs. To fill this void, a training program that targets the communication gaps of non-native English-speaking medical professionals with accent modification as the starting point was developed at Indiana University. This manuscript offers a blueprint for the development of this cutting-edge program and outlines its mission, structure and research findings. The paper also seeks to raise awareness of the needs of IMGs who are essential to the US healthcare system. The program described is offered as a resource for these professionals and for institutions of higher education seeking to invest in the professional development of their international faculty and students.
\end{abstract}

Keywords: accent reduction; accent modification; international medical graduates; communication skills training; intercultural communication; patient satisfaction 


\section{Introduction}

Effective communication is a critical part of quality healthcare delivery (Schyve, 2007). "If you can't communicate, it doesn't matter what you know" (Kurt, Silverman, \& Draper, 2005). Clear communication is essential for optimal interactions between colleagues, between physicians and other healthcare staff, and between physicians and patients. It lays the foundation for building strong healthcare teams and is closely related to patient healthcare outcomes (Stewart, 1995). Difficulties in communication influence patient satisfaction and treatment compliance. Additionally, they can increase provider stress (Ulrey, 2001), negatively impact interpersonal evaluations (Fuertes, Gottdiener, Martin, Gilbert, \& Giles, 2012), and hinder career advancement (Lee, Vaishnavi, Lau, Andriole, \& Jeffe, 2009; Munro, 2003). Native speakers of English deal with communication-related problems on a daily basis (Olson \& Windish, 2010). For non-native speakers of English, the nature and extent of these problems are simply exponential (McMahon, 2004). Their accents, which compound the problems of cross-cultural communication, have a strong influence on how others perceive them (Fuertes et al., 2012) and can even lead to discrimination (Myers, 2001).

\subsection{Statement of the Problem}

International medical graduates (IMGs) are an integral part of the U.S. healthcare system, representing 26\% of all U.S. physicians (M. Dill \& Salsberg, 2008); (Shah, Seifeld, \& Alvarez, 2010). They provide expertise in areas where significant shortages exist in the physician workforce (M. Dill \& Salsberg, 2008; M. J. Dill \& Poll-Hunter, 2010; Shah et al., 2010). They are indispensable in providing primary healthcare in underserved areas (Kostis \& Ahmad, 2004) and in regions where U.S. medical graduate (USMG) shortages are profound (Hagopian, Thompson, \& Hart, 2004; Thompson, Hagopian, Fordyce, \& Hart, 2009). In the foreseeable future, the U.S. public is likely to see an increasing dependence on IMGs in their medical care (Brotherton, Rockey, \& Etzel, 2005; McMahon, 2004).

While IMGs enrich the healthcare workforce with their knowledge and expertise, many of them struggle with communication-related problems. The pronunciation and intonation patterns of these non-native speakers of English often interfere with their ability to make themselves completely understood (Hall, Keely, Dojeiji, Byszewski, \& Marks, 2004; Mahajan \& Stark, 2007). Furthermore, IMGs often lack an understanding of regional dialects, colloquialisms and cultural nuances of communication (Fiscella \& Frankel, 2000; Kramer, 2006).

To overcome these barriers, IMGs must be trained to communicate effectively in a manner that is consistent with American English norms whenever necessary (Dorgan, Lang, Floyd, \& Kemp, 2009; Kramer, 2006). For patient safety and academic excellence, these highly educated, technologically competent professionals must demonstrate an equally high standard in all areas of communication - verbal and nonverbal, intra-professional, and interpersonal. In addition, all communication must be culturally appropriate (Ulrey, 2001). The Educational Commission for Foreign Medical Graduates (ECFMG) screens out the least prepared. However, those who pass the screening still face a steep learning curve in informal, regional 
American dialects (Dorgan et al., 2009). Therefore, a training program for the less prepared IMGs is very much needed.

\subsection{Questions Raised}

Given the dismal healthcare landscape, it is crucial to address a number of questions. If the United States continues to rely on more IMGs to provide healthcare to the public, would it be beneficial for all concerned to explore the IMGs' needs? Should these professionals have access to communication training for a more effective contribution to the workforce? Who will provide the training? Who will pay for it? What will be the format? Where will it be provided? What will determine the training program's success? Should the U.S. medical centers integrate this training into an already jam-packed curriculum or should it be an optional pursuit?

\subsection{Searching for Solutions}

There is sufficient literature pointing to the need for language training for IMGs in the United States, the communication challenges faced by them, and the strategies that could work effectively to counter some of these problems. However, it seems that hardly anyone has tried to address the problem at the institutional and regional level. In 2008, the School of Medicine faculty at Indiana University recognized the pressing need to provide communication training to a large number of IMGs in its workforce. Anticipating the continued and increasing dependence on IMGs to provide services in the future, the School decided to develop a resource on campus. A unique collaboration was established with liberal arts instructors specialized in English for special purposes. These collaborators from widely different and apparently unrelated fields worked closely together to develop a program called "American English Pronunciation for International Medical Professionals" (AEI). The primary focus of the program was to address the IMGs' spoken English language needs with accent modification as a starting point. This paper has outlined the three-year evolution of this program and a brief statistical analysis of its effectiveness.

\section{The AEI Program Description}

\subsection{Goals and Objectives}

Goals: The course has four overall goals for the participants:

1) to understand native speakers of American English,

2) to be understood by native speakers of American English,

3) to communicate more confidently, and

4) to communicate more effectively.

Objectives: Within the limitations of a short course, instructors keep participants focused on these objectives:

1) to recognize differences in an individual's English and standard American English by comparing and contrasting the two styles,

2) to recognize personal strengths and challenges in spoken English using three types of pre- and post-course assessments, 
3) to develop strategies for speech modification to build patient rapport and camaraderie with colleagues,

4) to explore emotions associated with communication,

5) to build new-language confidence, and

6) to develop strategies to self-monitor ongoing improvement in pronunciation skills.

\subsection{Course Criteria}

To address the day-to-day language needs, the AEI director at the medical school used the following course strategies:

- employing native English language instructors, including Teachers of English to Speakers of Other Languages (TESOL) — who were certified instructors,

- utilizing accredited materials and methods geared specifically for academic needs of international medical professionals in everyday communication,

- incorporating cultural issues for relevant application,

- offering individual attention through pre- and post-course assessments and limited enrollment, and

- remaining exclusive to physicians, researchers and medical students in the health system in year one, expanding to other university professionals in year two, and offering the program as a resource to professionals outside the university in subsequent years.

\subsection{Course Elements}

The focus of the instruction is on neutralization, not elimination, of international accents to retain the enriching flavor of diversity in the workplace. The course stresses preservation of native-language pride that reflects personal history and success.

The curriculum (List 1) focuses on traditional concerns (vowel/consonant sounds) as well as language nuances (stress/rhythm/intonation). Additional course elements include:

- textbook/CD for home, class and post-course use,

- relevant YouTube videos from external sources,

- learning-centered, large/small group activities,

- medical and everyday dialogue applications,

- discussions addressing participants' concerns, and

- additional topics geared for individual needs as determined by pre-course assessments

\subsection{Participant Recruitment}

Through an extensive campaign to department heads and potential participants via emails, Web sites, interdepartmental mail, flyers and meetings, the course was publicized to medical school faculty, residents, students and researchers. The graduate medical education office of Indiana University's School of Medicine joined hands with the program staff to publicize the course to all residents, fellows, and program directors. 


\subsection{Course Organization}

The initial three courses (beginning August and September 2008, and January 2009) had 12, 90-minute weekly classes going from 3 to $4: 30$ p.m. Following the feedback from a number of participants and supervisors, this schedule was changed to a shorter evening course with 2-hour weekly classes in February 2009 (eight classes, 5 to 7 p.m.). The enrollment cap was increased from 10 to 14 participants. This step made the instruction cost-effective. It also kept classes full and interactive when participants had inevitable scheduling conflicts. Twelve courses were completed between August 2008 and August 2012. Training took place at the medical school's affiliated hospital campuses, thus fostering collaboration among the departments and hospitals.

\subsection{Funding}

An education grant from the Indiana University's health foundation substantially reduced the participants' registration costs in the first two years (2008-2010). A subsidized registration fee was charged from the beginning. The funds raised from the fees were moved forward for use after the completion of the grant period. The subsidized fees were continued in the subsequent years with these funds. The Diversity Division of the Medical School's Office of Professional Development provided additional financial support. Although some departments offered full or partial fee support, participants often assumed the full cost.

\subsection{CME Credits}

From August 2009, Continuing Medical Education (CME) credits were awarded by the university, thus providing additional incentive for clinical faculty.

\subsection{Ongoing Support}

Based on the initial course success and requests from graduates, the program offered post-course workshops that helped the participants stay connected and reinforce common goals. Each set of five workshops focused on new language challenges and related topics (for example, impromptu speaking, fast-speech comprehension, cultural awareness, and informal vocabulary).

\subsection{Classroom Anecdotes and Observations}

For some participants, this course was their first formal language training in the United States. In this non-threatening environment, the participants' common needs and goals unified them and highly motivated them to learn together. For example, some people who had worked in the United States for several years expressed as much frustration with their English as those who had arrived four months earlier. They continued to receive blank looks or requests to repeat themselves. They were surprisingly supportive of one another, and camaraderie developed quickly. The feedback from the participants indicates that this is the right track to follow for their professional development. Many inevitably asked the same question; "I have worked at this university for years. Why did I not hear about this course before?" Some of the most heartwarming comments were from some of the medical school faculty who participated in the program. One senior physician with several years of experience in medical 
practice was very vocal in his appreciation for the availability of this service after years of searching for help. He said, "The course is a unique opportunity to polish up my language, but I wish I had this at the beginning of my career."

\section{Literature Review}

The IMGs have remained vital components of a select U.S. workforce. The sum total of their intellectual contributions is enormous, yet these talented individuals continue to face numerous challenges in their daily lives. Their foreign accents can have negative effects on how others perceive them. Striking accents can influence all aspects of their professional lives, including poor student evaluations (Fuertes et al., 2012) and racial discrimination (Kaafarani, 2009) (Moore \& Rhodenbaugh, 2002).

Mahajan et al. (Mahajan \& Stark, 2007) highlighted inappropriate communication skills as one of the barriers that influence the professional advancement of IMGs. Problems arise not only from difficulties with language but also from a difference in accents and lack of understanding of colloquial words (Fiscella \& Frankel, 2000).

In the foreseeable future, medical centers that assume responsibility for their IMGs' communicative proficiency will be addressing two needs: 1) greater and more equitable participation in the U.S. medical professions by highly competent IMGs and 2) a healthcare system that provides significant, high-quality answers to its critical shortage of professionals (McMahon, 2004).

Literature points to various tools for improving the IMGs' language learning: extensive orientation, cultural sensitivity training, increased peer/supervisor awareness, standardized patient experiences, immersion courses, and so on (Dorgan et al., 2009; McMahon, 2004; Yudkowsky, Downing, \& Sandlow, 2006). Some researchers (Hall et al., 2004; Mahajan \& Stark, 2007) have pointed to the need for induction programs and communication training courses specifically directed at IMGs as means to overcome these barriers. Jain et al. (Jain \& Krieger, 2011) studied the communication strategies used by international medical graduates in intercultural medical encounters. They suggested that recognizing accommodation strategies used by international physicians to overcome communication barriers could help train future international physicians who come to the United States. Early intervention will reduce the adjustment time spent in navigating through the system and experimenting with different strategies and will allow more time for patient care.

McMahon asserts that only IMGs with previous immersion among English speakers can reach fluency typically required for discussions about medical decisions (McMahon, 2004). Several researchers also state the immediate and long-term advantages of communication skills training (CST) in a small-group setting-ideally one that couples specific, clearly defined skills within a clear framework supported by well-aligned objectives and assessments (Brown \& Bylund, 2008; Fryer-Edwards et al., 2006). Formal English, even when fluently spoken, may be inadequate for some conversations that require advanced communication skills (e.g. giving bad news to a patient). The critical need is for clear, informal speech and pronunciation (Eggly, Musial, \& Smulowitz, 1999; Friedman, Sutnick, Stillman, Regan, \& 
Norcini, 1993; Sperling, 2006). As Bruijnzeels and Visser note: "Language is not the main feature of belonging...however, equal language is a prerequisite for effective communication" (Bruijnzeels \& Visser, 2005).

Most major cities offer a variety of language courses to assist non-native English speakers of all ages, backgrounds and goals. Community courses focus on conversational speech and basic writing skills while universities prepare incoming international students for scholastic demands in academic reading and writing, lectures, formal presentations, research, and so on (Cameron et al., 2009; IUPUI, 2012a, 2012b). Unfortunately, few IMGs take advantage of these courses; their reasons are complex and often very personal: a demanding and erratic work schedule, unrealistic self-assessments, high cost, and a certain degree of discomfort, to name a few. As a result, there is daily evidence of compromised communication with colleagues, patients and staff, which is largely ignored. There are numerous anecdotes but very little literature that brings this well-kept secret to the surface (Dorgan et al., 2009). While there have been sporadic attempts to address the need by some hospital departments in the United States, most of such programs have been short-lived. (Couper, 2006; Gareis \& Williams, 2004; Horvath, Coluccio, Foy, \& Pellegrini, 2004; Rosner, Dantzker, Walerstein, $\&$ Cohen, 1993). No one has ever tried to take on the issue at an institutional level. This program started at Indiana University is the first of its kind at the regional and perhaps the national level. It is a novel intervention that utilized a multidisciplinary approach and resulted in a huge impact, which is evident by its longevity. The program has lasted for five years since 2008, and there are plans for continuation and expansion of the program.

\section{Methodology}

The program had two overall objectives:

1) enabling neutralization of international accents through focused training in accent modification, and

2) assessing whether the teaching (both in content and process) has achieved the learning objectives.

To achieve the first objective, focused instruction as described in the syllabus was given. Classes were held once a week for 1.5 to 2 hours each for a total of 16-18 hours. A standard English pronunciation textbook with a CD was provided to each participant and used as a building block for materials from other books and online sources. Staying within the broad outline of the syllabus, each instructor was at liberty to use additional novel methods and materials.

The exercises involved large- and small-group practice sessions. In addition to the formal instruction within the framework of the defined syllabus, group activities, such as extempore presentations and discussions that focused on local events, were incorporated in the classes. Participants were also encouraged to talk about their communication difficulties and strategies that they used to manage situations. Colleague pairing was facilitated for continued practice after class.

To achieve the second objective, this study was designed to perform a need-analysis on the 
participants and to assess the efficacy of the program. This study was approved by the Institutional Review Board of Indiana University's School of Medicine. Three measures were used pre- and post-course.

1. Self-evaluation: Participants completed a two-page questionnaire that addressed their spoken language skills, their body language and positive/negative feelings about their communication, and their estimate of how much listeners understood them. The questions in the self-evaluation were mostly subjective in nature. A self-evaluation investigated each participant's self-perception of communication difficulties before the course and the improvement in these difficulties after the course.

2. Instructor's Assessment: For each participant, instructors provided a written assessment and numerical rating (Table 1) based on a brief audio-taped interview of text reading. The instructor's assessment provided objective measures to gauge the initial communication proficiency in six major areas and the post-training improvement in proficiency.

3. Objective Structured Communication Evaluation (OSCE): Independent Native English Speakers (NES) observed each participant in a simulated professional setting (office visit for clinicians, formal presentation for researchers) and completed a questionnaire with the same questions as the participant self-evaluation form. This independent evaluator provided an unbiased evaluation of the pre- and post-course communication proficiency and completed the assessment triad.

\section{Findings}

Twelve courses were completed over a four-year period (August 2008 to August 2012). One hundred and thirty-eight participants registered for these courses. Eighty-two percent of participants (113), representing 18 countries on five continents, attended at least two-thirds of the classes and completed all the pre- and post-course assessments. Participants belonged to diverse ethnic groups with Asians representing the largest single group (46\%). Participant ages ranged from 28 to over 50 years; male to female ratio was $44 \%$ to $56 \%$; time spent in the United States ranged from four months to 20 years. The participants' areas of clinical work and research were equally diverse; they came from all areas of healthcare. The following data analysis pertains to these 113 participants.

The study was undertaken to test the perceived efficacy of the course. Since the data are categorical and non-normal in nature, a paired-sample Wilcoxon signed ranks test was conducted. The data from self-evaluations by the participants, the independent evaluators and the course instructors suggest that the training was highly effective.

Participants rated their feelings about their communication in two ways:

1) the participant's perception of how well he or she communicates (e.g., "I am confident that I can communicate with patients."), and

2) the participant's underlying negative feelings associated with communication ability (e.g., "I worry that patients will not understand me; I believe patients have difficulty understanding me; I am afraid I will be misunderstood by patients"); this question was reverse-scored. 
Table 1 shows that, through the training program, the participants felt that they made significant improvement in all 11 areas in which they were trained. They reported a reduction in three negative feelings about their own ability to communicate with others in English. Based on the ratio of difference in the Sum of Ranks, the participants believed that their biggest improvements were in the following areas: the way they stressed words or syllables, their accuracy in pronouncing words, and their intonation and fluency of speech. A Mann-Whitney test of the perceptions of the male participants and female participants shows no significant difference between the two sexes across the board. Finally, the participants are grouped on the basis of the number of years in the United States (calculated from the years and months reported), but no conclusive trend in terms of their responses is found.

Table 1. Wilcoxon Signed Ranks Test on participants' pre- and post-rating of their English abilities

\begin{tabular}{|c|c|c|c|c|c|c|}
\hline & & $\mathrm{N}$ & $\begin{array}{l}\text { Mean } \\
\text { Rank }\end{array}$ & $\begin{array}{l}\text { Sum } \\
\text { of } \\
\text { Ranks } \\
\end{array}$ & $\mathrm{Z}$ & $\begin{array}{l}\text { Asymp. } \\
\text { Sig. } \\
\text { (2-tailed) }\end{array}$ \\
\hline \multirow{4}{*}{$\begin{array}{l}\text { The speed at which you } \\
\text { speak }\end{array}$} & Negative Ranks & 10 & 27 & 270 & \multirow{4}{*}{$-4.930^{\mathrm{a}}$} & \multirow{4}{*}{0.00} \\
\hline & Positive Ranks & 47 & 29.43 & 1383 & & \\
\hline & Ties & 52 & & & & \\
\hline & Total & 109 & & & & \\
\hline \multirow{4}{*}{$\begin{array}{l}\text { The volume at which you } \\
\text { speak }\end{array}$} & Negative Ranks & 14 & 30.18 & 422.5 & \multirow{4}{*}{$-4.265^{\mathrm{a}}$} & \multirow{4}{*}{0.00} \\
\hline & Positive Ranks & 48 & 31.89 & 1530.5 & & \\
\hline & Ties & 47 & & & & \\
\hline & Total & 109 & & & & \\
\hline \multirow{4}{*}{$\begin{array}{l}\text { How well you pronounce } \\
\text { words }\end{array}$} & Negative Ranks & 6 & 26.5 & 159 & \multirow{4}{*}{$-6.005^{\mathrm{a}}$} & \multirow{4}{*}{0.00} \\
\hline & Positive Ranks & 53 & 30.4 & 1611 & & \\
\hline & Ties & 49 & & & & \\
\hline & Total & 108 & & & & \\
\hline \multirow{4}{*}{$\begin{array}{l}\text { The way you stress words or } \\
\text { syllables }\end{array}$} & Negative Ranks & 4 & 34.88 & 139.5 & \multirow{4}{*}{$-6.758^{a}$} & \multirow{4}{*}{0.00} \\
\hline & Positive Ranks & 65 & 35.01 & 2275.5 & & \\
\hline & Ties & 40 & & & & \\
\hline & Total & 109 & & & & \\
\hline \multirow{4}{*}{$\begin{array}{l}\text { Your intonation (melody) } \\
\text { and fluency of speech }\end{array}$} & Negative Ranks & 7 & 30.29 & 212 & \multirow{4}{*}{$-5.692^{\mathrm{a}}$} & \multirow{4}{*}{0.00} \\
\hline & Positive Ranks & 54 & 31.09 & 1679 & & \\
\hline & Ties & 48 & & & & \\
\hline & Total & 109 & & & & \\
\hline \multirow{4}{*}{ The words you choose } & Negative Ranks & 15 & 37.4 & 561 & \multirow{4}{*}{$-2.650^{\mathrm{a}}$} & \multirow{4}{*}{0.00} \\
\hline & Positive Ranks & 44 & 27.48 & 1209 & & \\
\hline & Ties & 50 & & & & \\
\hline & Total & 109 & & & & \\
\hline Your body language & Negative Ranks & 15 & 26.5 & 397.5 & $-3.906^{\mathrm{a}}$ & 0.00 \\
\hline
\end{tabular}




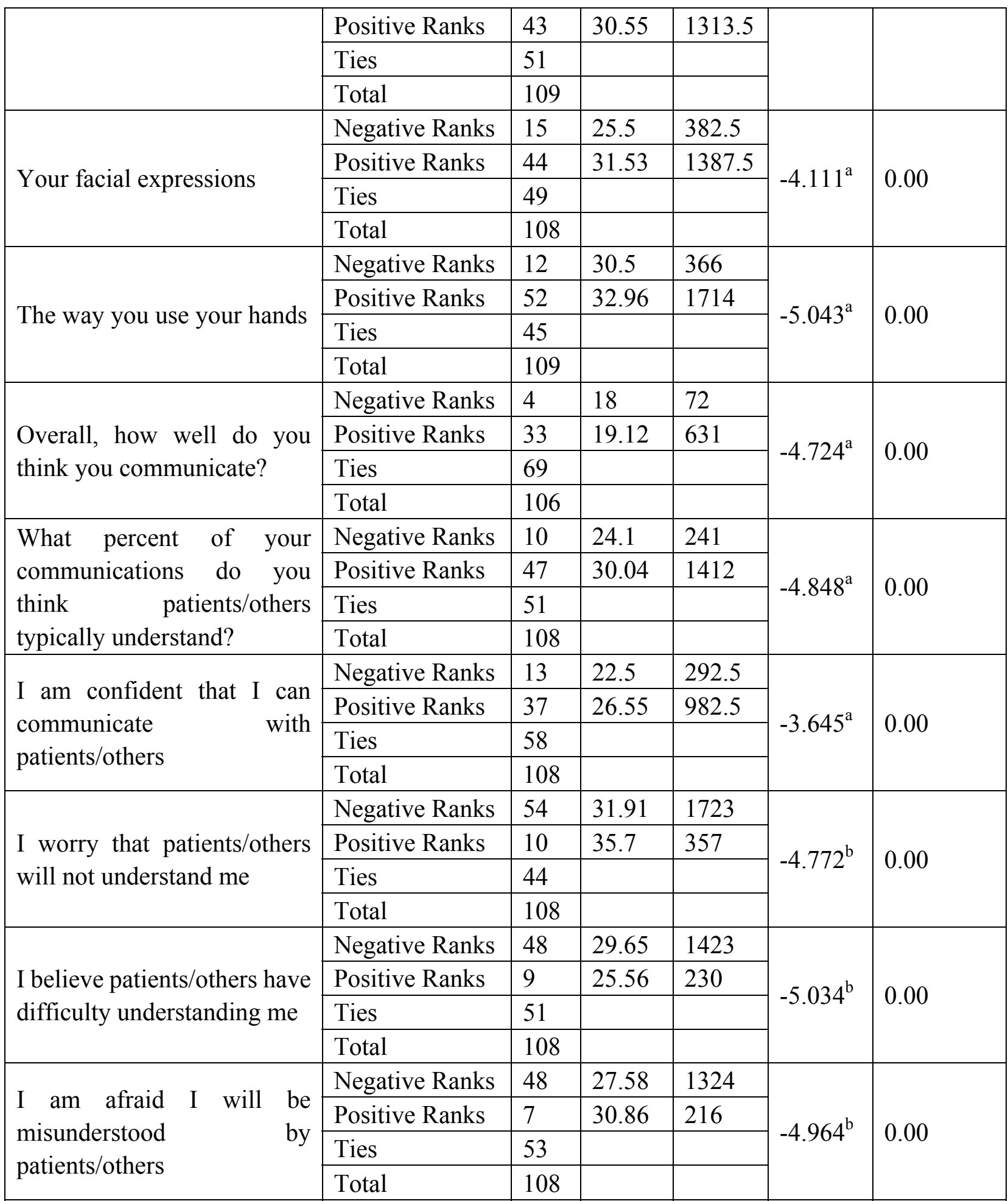

a. Based on negative ranks.

b. Based on positive ranks.

Table 2 shows how the Objective Structured Communication Evaluation conducted by two independent evaluators are correlated to the participants' rating. First, the analysis of the pre-course and post-course means from the evaluators showed that the independent 
evaluators believed that the participants had significantly improved their English language abilities in all the categories evaluated except four: fluency of speech, use of hands, facial expressions, and communication relative to native speakers of English. Second, the independent evaluators' rating and the participants' rating are highly correlated on 13 of the 22 counts. Third, the independent evaluators' rating was consistently higher than the participants' rating.

Correlations were done between the evaluators to ensure inter-rater reliability (Pearson $\mathrm{R}=0.914, \mathrm{p}<0.01)$. The scores of the two independent NESs were averaged for each question. Changes in those averaged pre-course scores and post-course scores were analyzed.

Table 2. Correlation between participants' rating and independent evaluators' rating

\begin{tabular}{|l|l|l|l|l|l|l|l|l|}
\hline & N & $\begin{array}{l}\text { Mean of } \\
\text { Particip } \\
\text { ants, } \\
\text { rating }\end{array}$ & $\begin{array}{l}\text { SD of } \\
\text { ants, } \\
\text { rating }\end{array}$ & $\begin{array}{l}\text { Mean of } \\
\text { OSCE } \\
\text { rating }\end{array}$ & $\begin{array}{l}\text { SD of } \\
\text { OSCE } \\
\text { rating }\end{array}$ & $\begin{array}{l}\text { Intraclass } \\
\text { Correlation } \\
\text { (Single } \\
\text { Measures) }\end{array}$ & $\begin{array}{l}\text { Kendall } \\
\text { s tau-b }\end{array}$ & Sig. \\
\hline $\begin{array}{l}\text { The speed at which you speak } \\
\text { (post) }\end{array}$ & 104 & 2.80 & 0.768 & 3.76 & 0.919 & 0.216 & 0.207 & $0.011^{*}$ \\
\hline The speed at which you speak (pre) & 106 & 2.45 & 0.841 & 3.08 & 1.096 & 0.219 & 0.174 & $0.045^{*}$ \\
\hline $\begin{array}{l}\text { The volume at which you speak } \\
\text { (post) }\end{array}$ & 104 & 2.83 & 0.794 & 3.84 & 0.849 & 0.202 & 0.168 & 0.075 \\
\hline $\begin{array}{l}\text { The volume at which you speak } \\
\text { (pre) }\end{array}$ & 107 & 2.43 & 0.891 & 3.37 & 0.906 & 0.091 & 0.098 & 0.275 \\
\hline $\begin{array}{l}\text { How well you pronounce words } \\
\text { (post) }\end{array}$ & 106 & 2.65 & 0.633 & 3.09 & 0.961 & 0.251 & 0.225 & 0.081 \\
\hline $\begin{array}{l}\text { How well you pronounce words } \\
\text { (pre) }\end{array}$ & 107 & 2.18 & 0.762 & 2.63 & 0.967 & 0.437 & 0.377 & $0.000^{*}$ \\
\hline $\begin{array}{l}\text { The way you stress words or } \\
\text { syllables (post) }\end{array}$ & 105 & 2.67 & 0.768 & 3.24 & 0.956 & 0.324 & 0.292 & $0.000^{*}$ \\
\hline $\begin{array}{l}\text { The way you stress words or } \\
\text { syllables (pre) }\end{array}$ & 110 & 1.96 & 0.789 & 2.64 & 0.974 & 0.310 & 0.256 & $0.002^{*}$ \\
\hline $\begin{array}{l}\text { Your intonation (melody) and } \\
\text { fluency of speech (post) }\end{array}$ & 105 & 2.61 & 0.727 & 3.37 & 0.933 & 0.333 & 0.343 & $0.000^{*}$ \\
\hline $\begin{array}{l}\text { Your intonation (melody) and } \\
\text { fluency of speech (pre) }\end{array}$ & 110 & 2.09 & 0.796 & 2.88 & 0.946 & 0.254 & 0.183 & $0.024^{*}$ \\
\hline The words you choose (post) & 106 & 3.15 & 0.687 & 3.97 & 0.668 & 0.217 & 0.204 & $0.024^{*}$ \\
\hline The words you choose (pre) & 110 & 2.95 & 0.892 & 3.60 & 0.837 & 0.037 & 0.044 & 0.631 \\
\hline Your body language (post) & 105 & 3.27 & 0.683 & 3.97 & 0.672 & 0.142 & 0.160 & 0.085 \\
\hline Your body language (pre) & 110 & 2.95 & 0.747 & 3.68 & 0.753 & -0.091 & -0.085 & 0.358 \\
\hline Your facial expressions (post) & 105 & 3.32 & 0.700 & 3.92 & 0.756 & 0.138 & 0.141 & 0.149 \\
\hline Your facial expressions (pre) & 101 & 2.95 & 0.805 & 3.76 & 0.723 & -0.191 & -0.191 & $0.048^{*}$ \\
\hline The way you use your hands (post) & 105 & 3.24 & 0.728 & 3.97 & 0.686 & 0.148 & 0.134 & 0.107 \\
\hline
\end{tabular}




\begin{tabular}{|l|l|l|l|l|l|l|l|l|}
\hline The way you use your hands (pre) & 101 & 2.83 & 0.762 & 3.73 & 0.760 & 0.042 & -0.037 & 0.690 \\
\hline $\begin{array}{l}\text { Overall, how well do you think you } \\
\text { communicate? (post) }\end{array}$ & 106 & 3.05 & 0.695 & 3.45 & 0.987 & 0.349 & 0.359 & $0.000^{*}$ \\
\hline $\begin{array}{l}\text { Overall, how well do you think you } \\
\text { communicate? (pre) }\end{array}$ & 108 & 2.76 & 0.852 & 3.08 & 0.898 & 0.380 & 0.344 & $0.000^{*}$ \\
\hline $\begin{array}{l}\text { What percent of your } \\
\text { communications do you think } \\
\text { patients/others typically } \\
\text { understand? (post) }\end{array}$ & 106 & 76.89 & 13.980 & 86.49 & 15.874 & 0.514 & 0.411 & $0.000^{*}$ \\
\hline $\begin{array}{l}\text { What percent of your } \\
\text { communications do you think } \\
\text { patients/others typically } \\
\text { understand? (pre) }\end{array}$ & 110 & 71.64 & 16.920 & 76.95 & 21.308 & 0.339 & 0.268 & $0.000^{*}$ \\
\hline
\end{tabular}

$* \mathrm{p}<0.05$.

Finally, instructors also noted improvement in most participants' verbal communication skills after the course. On a 1-to-5 scale of improving ordinance, the instructors' averaged pre-training evaluation (3.41) and averaged post-training evaluation (3.93) also were significantly different (pre $\mathrm{t}=32.1, \mathrm{df}=62$; post $\mathrm{t}=50.2, \mathrm{df}=59, \mathrm{p}<0.01$ ).

Thus, at the end of the program, the participants developed improved understanding of differences in spoken English between different cultures, and noted improvement in their ability to make themselves clearly understood; the independent NES's and instructors validated this perception with similar findings. The results from all three measures were statistically significant.

\subsection{Follow-Up Data}

Two to four months after the last class, the participants from the first six classes were requested to fill out a self-evaluation again. Twenty-eight participants submitted the evaluation, which provides the follow-up data. Compared to the post-class data, the follow-up data show significantly greater improvement in speed and volume of their speech $(p<0.05)$. Although there was further improvement in the choice of words and body language, the gains were not statistically significant $(\mathrm{p}<0.10)$. A larger number of participants are needed to get potentially significant results for the other measures.

\section{Program Strengths}

Collaboration between liberal arts instructors, medical school professionals and researchers helped in the development and ongoing improvement of the program. The physicians were able to identify the problems and give feedback on the strategies that were effective in the classroom. The instructors modified teaching methods to suit the participants' needs, and the researchers provided feedback on evidence of efficacy. Group classes with small class size made the course cost-effective while assuring individual attention. Voluntary sign-up for the program assured self-motivation and readiness to change. The diversity of the participants both in ethnicity and in professional background kept the classes interesting while fostering 
collaboration among the departments. Support by the medical school's faculty development office ensured visibility. Continuing education credits awarded by the school offered an additional incentive for the participants to invest time in this area of professional development.

\section{Program Limitations and Challenges}

Despite the course's broad appeal and positive research findings, the program has faced challenges on several fronts. The following were the most notable:

\subsection{Program Implementation}

The participants' professional roles at the medical center can limit their physical and mental participation. In addition, each one has his or her perception of an ideal program, which can influence satisfaction with course logistics and personal progress. For some participants, even the nominal fee is a hindrance. The continuing medical education (CME) credits add value and may offset the expense. The program's grant covered costs initially (instructor salary, administrative expenses, reduction of registration fees, textbooks and so on), but the lack of protected time for the program director and the part-time staff challenged team coordination. There was an ongoing adjustment of class logistics and the search for better class times and locations for such a diverse and widely scattered group of participants.

\subsection{Research Implementation}

One of the most time-consuming challenges was data collecting for this study. Initial assessments took place outside of the class time, which resulted in delays, no-shows, and incomplete assessments - thus loss of data and feedback for the program. In addition, assuring consistency in measures was an ongoing battle. Questions were qualitative; variables abounded. For example, participants came from a variety of linguistic, cultural and educational backgrounds and were at different levels of English proficiency. Evaluators, too, applied different interpretations to communicative proficiency in their assessments. Each of these variables could have compromised the data's accuracy. Finally, the variables in language acquisition (for example, a person's abilities, self-awareness, confidence, and strategies) and individual circumstances, such as motivating factors, mentors, and schedule, were difficult to control in research.

\section{Discussion and Conclusions}

IMGs are a vital component of the U.S. healthcare system. They have special professional development needs, which are often overlooked by academic and non-academic institutions both in the United States and abroad. There is an increasing need for programs like AEI to meet the training needs of international medical professionals. This program has offered these professionals an opportunity to improve their communication skills for expedited acculturation to the United States. The popularity of the program, its broad appeal to all age groups, and the feedback from participants showed that these professionals appreciated the need for communication training that focused on accent modification. The participants found this method of improving the clarity of communication more helpful than just immersion in 
the native English-speaking culture without understanding the differences. The research results show that they benefited from such a structured formal training. In addition to the improvement in the verbal and non-verbal communication, they reported increased feelings of confidence and efficiency after the training. The question of whether a program such as this one has resulted in sustained accent modification still needs to be explored in a longitudinal study in the future. Limited follow-up data suggest the likelihood of lasting changes with ongoing practice.

The findings from this program can inform the delivery of communication skill training. Institutions conducting educational programs that prepare foreign-trained health professionals for accreditation in a particular country should consider the students' communication competencies and offer appropriate training as an integrated component of the training programs. Medical schools and residency programs should incorporate evidence-based training that reduces language and communication barriers into their curricula for IMGs in a timely manner. Some participants may not feel motivated to enroll in the program until they have personal interactions in which their highly accented speech has interfered with their ability to communicate clearly. Timely access to appropriate communication training programs will enable IMGs to achieve their full potential as healthcare providers while they improve relationships with patients, colleagues, and hospital staff. This intervention, in turn, may pay huge dividends for the healthcare institutions through increased patient satisfaction.

\section{Further Development}

As more people are engaged in the program's goals, a greater role for the program is anticipated within a medical center, city, and national setting. There has been a firm commitment to its value and its positive influence on the participants within the medical school. Administrators have been enthusiastic about and helpful in getting the word out. The medical center's support has remained critical not only to the program's credibility but also to its longevity. The ultimate goal is to have several levels of the classes with additional complementary courses. Participants will be pre-screened and assigned to these classes based on the level of English proficiency, accent comprehensibility, grammar accuracy, and intercultural understanding. Participants who invest in their communication success will have the option to be a part of the program's network for additional ongoing support. A nominal yearly fee for membership will provide eligibility for discounts in all workshops. Future plans also include offering these classes to participants in remote locations through videoconferencing and online learning tools.

\section{Acknowledgments}

The authors would like thank the following organizations and individuals who have contributed significantly to the development, implementation and research analysis of the program: Pam Ruble and Jeff Burnham: ESL instructors, Kim Saxton: Kelley School of Business, Sarah Lang, Deborah Burleson, Crystal Haney and Janice Wall: Indiana University School of Medicine. 
The AEI program was made possible by a two-year education grant, VFE 201 from the Health Values program at Indiana University.

Thanks also go to Stephanie Huang, a student from the University of Houston Law Center, for proofreading the manuscript of this article.

\section{References}

Brotherton, S. E., Rockey, P. H., \& Etzel, S. I. (2005). US graduate medical education, 2004-2005: trends in primary care specialties. JAMA, 294(9), 1075-1082. http://dx.doi.org/10.1001/jama.294.9.1075

Brown, R. F., \& Bylund, C. L. (2008). Communication Skills Training: Describing a New Conceptual Model. Academic Medicine, 83(1), 37-44.

Bruijnzeels, M., \& Visser, A. (2005). Intercultural doctor-patient relational outcomes: need more to be studied. Patient Educ Couns, 57(2), 151-152. http://dx.doi.org/10.1016/j.pec.20 05.03.002

Cameron, C., Deming, S. P., Notzon, B., Cantor, S. B., Broglio, K. R., \& Pagel, W. (2009). Scientific writing training for academic physicians of diverse language backgrounds. Acad Med, 84(4), 505-510. http://dx.doi.org/10.1097/ACM.0b013e31819a7e6d

Couper. (2006). The short and long term effects of pronuciation instruction. Prospect, 21(1), 46-60.

Dill, M. J., \& Poll-Hunter, N. I. (2010). AM last page: Increasing workforce diversity. Acad Med, 85(1), 179. http://dx.doi.org/10.1097/ACM.0b013e3181c91b2b

Dill, M., \& Salsberg, E. (2008). The complexities of Physician supply and demand: projections through 2015 (C. f. w. studies, Trans.) (pp. 5-77): Association of American Medical Colleges.

Dorgan, K. A., Lang, F., Floyd, M., \& Kemp, E. (2009). International medical graduate-patient communication: a qualitative analysis of perceived barriers. Acad Med, 84(11), 1567-1575. http://dx.doi.org/10.1097/ACM.0b013e3181baf5b1

Eggly, S., Musial, J., \& Smulowitz, J. (1999). The relationship between English language proficiency and success as a medical resident. English for Specific Purposes, 18(2), 201-208.

Fiscella, K., \& Frankel, R. (2000). Overcoming cultural barriers: international medical graduates in the United States. JAMA, 283(13), 1751. http://dx.doi.org/10.1001/jama.28 3.13.1751

Friedman, M., Sutnick, A. I., Stillman, P. L., Regan, M. B., \& Norcini, J. J. (1993). The Relationship of Spoken-English Proficiencies of Foreign Medical-School Graduates to Their Clinical Competence. Academic Medicine, 68(10), S1-S3. http://dx.doi.org/10.1097/0000 1888-1 99310000-00027

Fryer-Edwards, K., Arnold, R. M., Baile, W., Tulsky, J. A., Petracca, F., \& Back, A. (2006). 
Reflective teaching practices: an approach to teaching communication skills in a small-group setting. Acad Med, 81(7), 638-644. http://dx.doi.org/10.1097/01.ACM.0000232414.43142.45

Fuertes, J. N., Gottdiener, W. H., Martin, H., Gilbert, T. C., \& Giles, H. (2012). A meta-analysis of the effects of speakers' accents on interpersonal evaluations. European Journal of Social Psychology, 42(1), 120-133. http://dx.doi.org/10.1002/ejsp.862

Gareis, E., \& Williams, L. (2004). International Faculty Development for Full-Time and Adjunct Faculty: A Program Description. Journal of Faculty Development, 20(1), 45-56.

Hagopian, A., Thompson, M. J., Kaltenbach, E., \& Hart, L. G. (2004). The role of international medical graduates in America's small rural critical access hospitals. The Journal of Rural Health, 20(1), 52-58.

Hall, P., Keely, E., Dojeiji, S., Byszewski, A., \& Marks, M. (2004). Communication skills, cultural challenges and individual support: challenges of international medical graduates in a Canadian healthcare environment. Med Teach, 26(2), 120-125. http://dx.doi.org/10.1080/01 421590310001653982

Horvath, K., Coluccio, G., Foy, H., \& Pellegrini, C. (2004). A program for successful integration of international medical graduates (IMGs) into US surgical residency training. Current Surgery, 61(5), 492-498. http://dx.doi.org/10.1016/jcursur.2004.06.011

IUPUI. (2012a). Continuing Education. Retrieved from https://www.cln.iupui.edu/apps/cata $\log$ index.asp?site=IUPUI

IUPUI. (2012b). English for Academic Purposes. Retrieved 2012 from http://liberalarts.iupui.edu/english/index.php/academics/eap/eap_home

Jain, P., \& Krieger, J. L. (2011). Moving beyond the language barrier: The communication strategies used by international medical graduates in intercultural medical encounters. Patient Education and Counseling, 84(1), 98-104. http://dx.doi.org/DOI 10.1016/j.pec.2010.06.022

Kaafarani, H. M. (2009). International medical graduates in surgery: facing challenges and breaking stereotypes. Am J Surg, 198(1), 153-154. http://dx.doi.org/10.1016/j.amjsurg.20 08.08.004

Kostis, J. B., \& Ahmad, B. (2004). International medical graduates and the cardiology workforce. $J$ Am Coll Cardiol, 44(6), 1172-1174. http://dx.doi.org/10.1016/j.jacc.2 004.05 .081

Kramer, M. (2006). Educational challenges of international medical graduates in psychiatric residencies. J Am Acad Psychoanal Dyn Psychiatry, 34(1), 163-171. http://dx.doi.org/ 10.1521/jaap.2006.34.1.163

Kurt, S., Silverman, J., \& Draper, J. (2005). Teaching and Learning Communication Skills in Medicine (Second ed.). Oxford: Radcliffe publishing.

Lee, K. B., Vaishnavi, S. N., Lau, S. K., Andriole, D. A., \& Jeffe, D. B. (2009). Cultural competency in medical education: demographic differences associated with medical student 
communication styles and clinical clerkship feedback. J Natl Med Assoc, 101(2), 116-126.

Mahajan, J., \& Stark, P. (2007). Barriers to education of overseas doctors in paediatrics: a qualitative study in South Yorkshire. Arch Dis Child, 92(3), 219-223. http://dx.doi.org/10.1136/adc.2006.098939

McMahon, G. T. (2004). Coming to America--international medical graduates in the United States. N Engl J Med, 350(24), 2435-2437. http://dx.doi.org/10.1056/NEJMp038221

Moore, R. A., \& Rhodenbaugh, E. J. (2002). The unkindest cut of all: Are international medical school graduates subjected to discrimination by general surgery residency programs? Current surgery, 59(2), 228-236.

Munro, M. J. (2003). A Primer on Accent Discrimination in the Canadian Context. TESL Canada J, 20(2), 38-51.

Myers, M. A. (2001). Accent Discrimination: An Intercultural Problematic. Florida Comm J., 29(1), 14-27.

Olson, D. P., \& Windish, D. M. (2010). Communication discrepancies between physicians and hospitalized patients. Archives of internal medicine, 170(15), 1302-1307.

Rosner, F., Dantzker, D. R., Walerstein, S., \& Cohen, S. (1993). Intensive one-week orientation for foreign medical graduates entering an internal medicine residency program. $J$ Gen Intern Med, 8(5), 264-265.

Schyve, P. M. (2007). Language Differences as a Barrier to Quality and Safety in HealthCare: The Joint Commission Perspective. J Gen Intern Med, 22(2), 360-361.

Shah, J., Seifeld, R., \& Alvarez, H. E. A. (2010). International Medical Graduates in American Medicine: Contemporary challenges and opportunities.

Sperling, D. (2006, Feb -March). Teacher Discussion Forum - English for Specific Purposes. Dave's ESL Cafe: Retrieved February 9, 2010, from http://forums.eslcafe.com/teacher/vie wtopic.php? $=24055$

Stewart, M. A. (1995). Effective physician-patient communication and health outcomes: a review. CMAJ, 152(9), 1423-1433.

Thompson, M. J., Hagopian, A., Fordyce, M., \& Hart, L. G. (2009). Do International Medical Graduates (IMGs) "Fill the Gap" in Rural Primary Care in the United States? A National Study. Journal of Rural Health, 25(2), 124-134.

Ulrey, K. (2001). Intercultural communication between patients and healthcare providers: an exploration of intercultural communication effectiveness, cultural sensitivity, stress, and anxiety. Health Communication, 13(4), 449-463.

Yudkowsky, R., Downing, S. M., \& Sandlow, L. J. (2006). Developing an institution-based assessment of resident communication and interpersonal skills. Acad Med, 81(12), 1115-1122. http://dx.doi.org/10.1097/01.ACM.0000246752.00689.bf 


\section{Copyright Disclaimer}

Copyright reserved by the author(s).

This article is an open-access article distributed under the terms and conditions of the Creative Commons Attribution license (http://creativecommons.org/licenses/by/3.0/). 